\title{
TEORES DE CÁLCIO E DE FERRO EM FOLHAS DE ORA-PRO-NÓBIS EM FUNÇÃO DA ADIÇÃO DE COMPOSTO ORGÂNICO NO SUBSTRATO E DE LÂMINAS DE IRRIGAÇÃO
}

\author{
Reginaldo Rodrigues de Andrade ${ }^{1}$, João Antônio Galbiatti², Carla Regina Amorim dos Anjos Queiroz ${ }^{3}$, \\ Luiz Carlos Pavani ${ }^{4}$
}

\begin{abstract}
RESUMO - A Ora-pro-nóbis (Pereskia aculeata Mill.) é uma hortaliça não-convencional cujas folhas são comestíveis e ricas em cálcio $(\mathrm{Ca})$ e o ferro $(\mathrm{Fe})$, elementos importantes na dieta humana. Plantada em quintais para consumo quase que exclusivamente caseiro tem, mais recentemente, aumentado o seu cultivo em escala comercial, mas sem muito conhecimento de manejo da cultura. Resíduos orgânicos podem, após compostagem, ser utilizados na composição de substratos alternativos de baixo custo e com benefícios para a planta e para o ambiente. O manejo da irrigação por sua vez permite controle do momento e da quantidade de água a ser aplicada nas culturas. O objetivo deste trabalho foi verificar a influência da utilização de composto orgânico e de lâminas de irrigação nos teores de Ca e Fe em folhas de Ora-pro-nóbis. Para isso, em ambiente protegido, foram preparados substratos com solo e areia misturados a doses de composto orgânico (CO) de $0 \%, 15 \%$, $30 \%, 45 \%$ e $60 \%$ do volume total. Mudas de Ora-pro-nóbis plantadas nesses substratos foram irrigadas com lâminas de irrigação (LI) correspondentes a 50\%,75\% e 100\% da evapotranspiração de referência (Et $\left.\mathrm{E}_{0}\right)$. Aos 122 dias de cultivo as folhas foram colhidas e determinados os teores de cálcio e de ferro. O aumento da lâmina de irrigação de $50 \%$ para $100 \%$ da evapotranspiração de referência aumenta os teores de Ca e de $\mathrm{Fe}$, enquanto o aumento das doses do composto orgânico no substrato de $0 \%$ para $60 \%$ tem efeito deletério nos teores desses elementos nas folhas.
\end{abstract}

Palavras chave: gestão de resíduos, hortaliça não-convencional comestível, Pereskia aculeata Mill., substrato para plantio.

\section{CALCIUM AND IRON CONTENTS IN LEAVES OF ORA-PRO-NÓBIS AS A FUNCTION OF THE ADDITION OF ORGANIC COMPOUND IN THE SUBSTRATE AND OF IRRIGATION DEPTHS}

\begin{abstract}
The Ora-pro-nóbis (Pereskia aculeata Mill.) is an unconventional vegetable whose leaves are edible and rich in calcium ( $\mathrm{Ca}$ ) and iron ( $\mathrm{Fe}$ ), that are important substances in human diet. It is planted in backyards for home consumption, almost exclusively, although its growth on a commercial scale has been initiated, on a poor knowledge of its crop management. Organic wastes can be used after composting in the composition of alternative low coast substrates and with benefits to the crops and the environment. The management of irrigation in turns allows control of the time and amount of water to be applied in crops. The aim of this work was to verify the influence of the use of organic compost and irrigation depths in Ca and Fe contents on leaves of Ora-pro-nóbis. For this, in a protected environment, soil and sand substrates
\end{abstract}

\footnotetext{
${ }^{1}$ Licenciado em Química, Professor Doutor, Instituto Federal de Educação, Ciência e Tecnologia do Triângulo Mineiro, Campus Uberlândia, Uberlândia-MG. Email: reginaldoandrade@iftm.edu.br

${ }^{2}$ Eng $^{\circ}$ Agrônomo, Professor Titular, Aposentado, Departamento de Engenharia Rural, UNESP-Jaboticabal, SP. Email; galbi@fcav.unesp.br ${ }^{3}$ Licenciada em Química, Professora Doutora, Campus Uberlândia, Instituto Federal do Triângulo Mineiro, Uberlândia-MG. Email: carlaregina@iftm.edu.br

${ }^{4}$ Eng. Agrônomo, Professor Assistente Doutor, Aposentado, Departamento de Engenharia Rural, UNESP, Jaboticabal, SP. Email: pavani.1c@gmail.com
} 
were prepared at $0 \%, 15 \%, 30 \%, 45 \%$ and $60 \%$ of the total volume of organic compound. The seedlings planted on these substrates were irrigated with irrigation depths corresponding to 50\%, 75\% and $100 \%$ of the reference evapotranspiration. At 122 days of plant growth the leaves were harvested and the calcium and iron contents were determined. Increasing the irrigation depth from $50 \%$ to $100 \%$ of the reference evapotranspiration increases the Ca and Fe contents in the leaves while increasing the doses of the organic compound in the substrate has an adverse effect.

Keywords: unconventional edible vegetable, Pereskia aculeata Mill., substrate for planting, waste management.

\section{INTRODUÇÃO}

Os minerais, importantes para a contratilidade muscular, a coagulação sanguínea, os processos digestivos, o transporte de oxigênio e outros, correspondem a $4 \%$ da composição total do corpo humano, sendo que $1,5 \%$ desses corresponde ao cálcio, $1 \%$ ao fósforo e $1,5 \%$ ao restante dos demais minerais. Dentre suas importantes funções estão a contratilidade muscular, a coagulação sanguínea, os processos digestivos, o transporte de oxigênio e outros (Franco, 2004). Devido às perdas diárias de minerais pelo organismo, sua reposição deve ser feita por meio de fontes externas, das quais os alimentos naturais são as principais, tanto as de origem animal quanto as de origem vegetal (Kinupp \& Barros, 2008).

Os vegetais também não fabricam minerais para o seu metabolismo, crescimento e desenvolvimento, mas os absorvem diretamente do meio em que se desenvolvem, principalmente através do seu sistema radicular. No caso do cálcio e do ferro, a absorção pelas raízes ocorre, em maior proporção, de forma passiva, por transporte de massa de acordo com a entrada de água (Soares et al., 2001; Prado, 2008). Em condições de déficit hídrico no meio radicular, por longo tempo, a corrente transpiratória pode ser severamente restringida e, como consequência, também poderá ser reduzido o transporte de cálcio e de ferro das raízes para a parte aérea das plantas (Ferreira et al., 2008).

Consideram-se como hortaliças não convencionais aquelas que com distribuição limitada à determinada região, não fazem parte de uma cadeia produtiva à semelhança das hortaliças convencionais. Essas hortaliças podem exercer grande influência na alimentação e na cultura de populações tradicionais (Brasil, 2010).

As plantas de Ora-pro-nóbis apresentam nas folhas, alto teor de aminoácidos essenciais, de cálcio, de ferro e de fibras, além de ausência de toxicidade. Tais qualidades fazem-na promissora como fonte de alimento de boa qualidade ao alcance da população (Takeiti et al., 2009; Souza et al., 2016).

São pouco conhecidas as formas de utilização dessa espécie, bem como técnicas para o seu cultivo. Ela pode ser cultivada em ambiente protegido com uso de substratos de composição variável, contendo, por exemplo, compostos orgânicos oriundos da compostagem de resíduos sólidos. De acordo com Silva Júnior et al. (2014), esses substratos são uma alternativa de baixo custo e alta disponibilidade, que, ao mesmo tempo, é uma alternativa à reciclagem desses resíduos.

A compostagem propicia melhorias nas propriedades do solo (aumento do teor de matéria orgânica, aumento da capacidade de troca catiônica, aumento na capacidade de retenção de água, elevação do $\mathrm{pH}$, redução da acidez potencial e aumento da disponibilidade de fósforo, potássio, cálcio e magnésio), na nutrição e na produção dos vegetais (Abreu Júnior et al., 2001; Kiehl, 2010).

As plantas dependem da quantidade de água disponível na zona radicular e, em épocas de ocorrência de déficit hídrico no solo ou no substrato, é necessária a utilização de um manejo adequado de água. Para isso, ensaios com lâminas de irrigação definidas em função das condições evapotranspirométricas do local e na época de cultivo, são fundamentais (Bezerra et al., 2009).

Em função do exposto, este trabalho teve por objetivo avaliar os teores de cálcio e de ferro nas folhas de Ora-pro-nóbis em função de lâminas de irrigação e de doses de composto orgânico misturado ao solo do substrato.

\section{MATERIAL E MÉTODOS}

O experimento foi desenvolvido no período de 27 de abril a 27 de agosto de 2010, em ambiente protegido, sob filme de plástico transparente de $150 \mu \mathrm{m}$ de espessura e que constitui também, uma das paredes, sendo as demais constituídas por sombrite com $50 \%$ de retenção 
de luz, anexo ao viveiro de mudas do Instituto Federal do Triângulo Mineiro - Campus Uberlândia(IFTM), localizado a uma altitude de $633 \mathrm{~m}$, latitude de $18^{\circ} 45^{\prime} 48^{\prime}$ "S e longitude de $48^{\circ} 17^{\prime} 20^{\prime \prime} \mathrm{W}$.

O delineamento experimental utilizado foi o inteiramente casualizado (DIC) com 15 tratamentos, arranjados em esquema fatorial $5 \times 3$ (5 substratos e 3 níveis de irrigação), com 4 repetições e 2 plantas por repetição.

Os substratos foram constituídos da mistura de solo e areia média à qual foi adicionada composto orgânico nas proporções apresentadas na Tabela 1 .

O composto orgânico (CO) utilizado para a formação dos substratos foi um composto orgânico comercial produzido por meio de compostagem, a partir de resíduos sólidos agroindustriais e industriais do município de Uberlândia-MG.

A areia empregada na mistura foi areia média de rio que foi lavada e seca à sombra, em temperatura ambiente. O solo foi retirado da camada de 0 a $20 \mathrm{~cm}$ de uma área próxima à experimental e seco à sombra.

Os três componentes do substrato foram peneirados separadamente em malha de $4 \mathrm{~mm}$ antes de fazerem parte da mistura. Antes da mistura dos componentes, amostras do solo e do composto orgânico foram coletadas e submetidas a análises físicas e químicas do solo e químicas do composto orgânico incluindo elementos potencialmente tóxicos como níquel, chumbo, cádmio e cromo (Tabela 2).

Os substratos preparados (Tabela 1) foram colocados individualmente em sacos de plástico juntamente com 2,66 g de adubo formulação 4:14:8 $\left(\mathrm{N}: \mathrm{P}_{2} \mathrm{O}_{5}: \mathrm{K}_{2} \mathrm{O}\right.$ ) seguindo o adotado por Tofanelli \& Resende (2011), uma vez que não há na literatura especializada, até o momento, recomendação de adubação específica para Ora-pro-nóbis com base na análise química do solo. Também foi adicionado $0,77 \mathrm{~g}$ de calcário dolomítico por vaso, PRNT 93,8\%, para elevar a saturação por bases do solo do substrato para $70 \%$.

Posteriormente, procedeu-se a homogeneização e colocação dos substratos em vasos com capacidade para $1700 \mathrm{~cm}^{3}$ e com as seguintes dimensões internas: diâmetro superior de $12 \mathrm{~cm}$, diâmetro inferior $9 \mathrm{~cm}$ e altura $20 \mathrm{~cm}$. Depois disso, nos vasos de cada tratamento $\mathrm{S} 1, \mathrm{~S} 2, \mathrm{~S} 3, \mathrm{~S} 4$ e S5 foram adicionados, respectivamente, 630, 640, 660, 690 e $695 \mathrm{~mL}$ de água, considerando as médias das quantidades necessárias para que, em 3 vasos de cada tratamento, iniciasse a drenagem do excesso de água pelo fundo do vaso, aproximando-se assim da "capacidade de vaso" para cada substrato. Após a adição da água, os vasos foram cobertos com lâminas de plástico fixadas com elásticos, com dois orifícios para troca de ar com o ambiente, permanecendo assim durante 11 dias em incubação para a reação do calcário com o substrato. Depois desse período, os substratos foram analisados quanto às suas características químicas (Tabela 3 ).

Para o plantio das mudas foram escolhidas 120 de 700 estacas caulinares com $20 \mathrm{~cm}$ de comprimento, as mais homogêneas em coloração, número de gemas e diâmetro medido no ponto médio do comprimento das estacas que variaram de $11,36 \mathrm{~cm}$ a $12,57 \mathrm{~cm}$. As estacas foram retiradas de uma única planta matriz de Ora-pro-nóbis, que foi confirmada como sendo Pereskia aculeata Mill. por especialista do Jardim Botânico do Rio de Janeiro, por meio do envio de fotografias detalhadas das flores dessa planta. Essas estacas, após passarem por processo de desinfestação por imersão durante 5 minutos em solução de hipoclorito de sódio $(0,5 \%)$ e lavagem em água corrente, por 5 minutos, foram

Tabela 1 - Composição dos substratos para plantio das estacas e cultivo de Ora-pro-nóbis

\begin{tabular}{|c|c|c|c|c|}
\hline \multirow{2}{*}{ Substratos } & \multicolumn{2}{|c|}{ Composto orgânico } & \multicolumn{2}{|c|}{ Areia média + Solo ${ }^{(a)}$} \\
\hline & $(\%)$ & Volume $\left(\mathrm{cm}^{3}\right)$ & $(\%)$ & Volume $\left(\mathrm{cm}^{3}\right)$ \\
\hline S1 & 0 & 0 & 100 & 1700 \\
\hline S2 & 15 & 255 & 85 & 1445 \\
\hline $\mathrm{S} 3$ & 30 & 510 & 70 & 1190 \\
\hline S4 & 45 & 765 & 55 & 935 \\
\hline S5 & 60 & 1020 & 40 & 680 \\
\hline
\end{tabular}

(a) Latossolo Vermelho distroférrico típico (EMBRAPA, 2013). 
Tabela 2 - Resultado da análise química do composto orgânico (CO) e física e química do solo

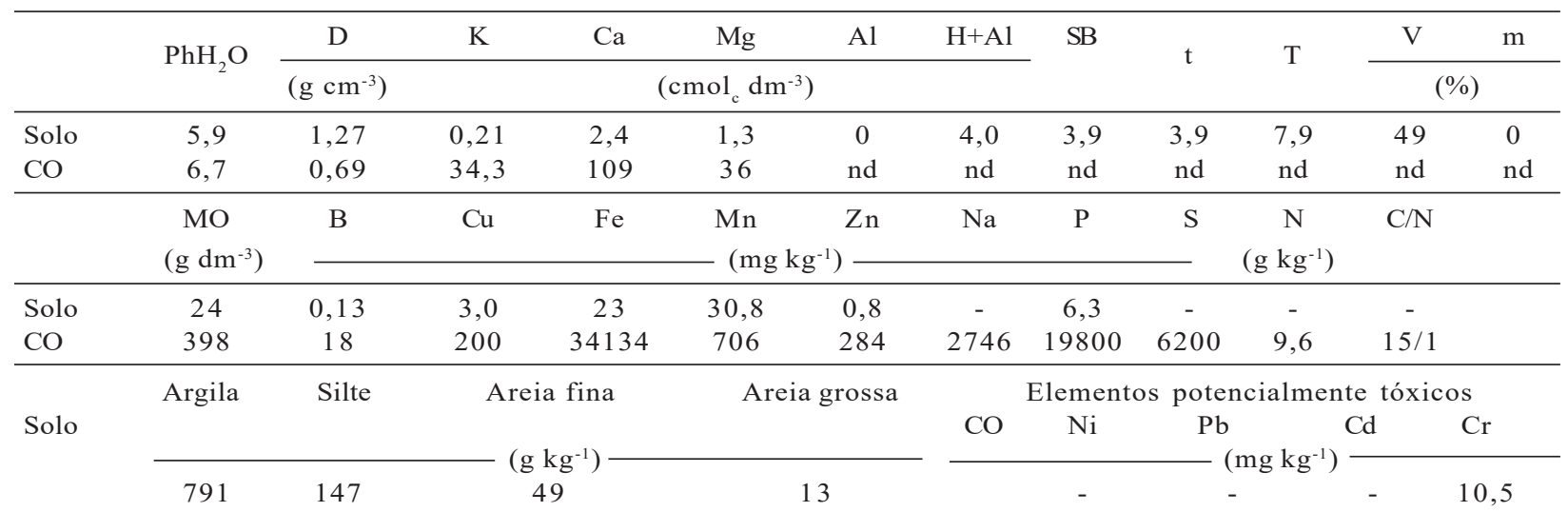

pH - Potencial hidrogeniônico; D - densidade; $\mathrm{K}$ - potássio, Ca - cálcio; Mg - magnésio; Al - alumínio; H + Al - acidez potencial; $\mathrm{SB}$ - soma de bases; $\mathrm{t}$ - CTC efetiva; T - CTC a pH 7,0; V - saturação por bases; $\mathrm{m}$ - saturação por alumínio; MO - matéria orgânica; $\mathrm{B}$ - Boro; $\mathrm{Cu}$ - Cobre; $\mathrm{Fe}$ - ferro; $\mathrm{Mn}$ - manganês; $\mathrm{Zn}$ - zinco; $\mathrm{Na}$ - sódio; $\mathrm{P}$ - fósforo; $\mathrm{S}$ - enxofre; $\mathrm{N}$ - nitrogênio; $\mathrm{C} / \mathrm{N}$ - relação carbono-nitrogênio; $\mathrm{Ni}$ - níquel; $\mathrm{Pb}$ - chumbo; $\mathrm{Cd}$ - cádmio; $\mathrm{Cr}$ - cromo; nd = não determinado; traço (-) significa não detectado pela análise.

Tabela 3 - Características químicas dos substratos após a incubação

\begin{tabular}{|c|c|c|c|c|c|c|c|c|c|c|c|c|}
\hline$\% \mathrm{CO}$ & $\mathrm{pH}$ & $\mathrm{P}$ & K & $\mathrm{Ca}$ & $\mathrm{Mg}$ & $\mathrm{Al}$ & $\mathrm{H}+\mathrm{Al}$ & SB & $\mathrm{t}$ & $\mathrm{T}$ & V & $\mathrm{m}$ \\
\hline & $\left(\mathrm{H}_{2} \mathrm{O}\right)$ & $\left(\mathrm{mg} \mathrm{dm}^{-3}\right)$ & & & 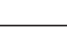 & 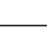 & $\mathrm{mol}_{\mathrm{c}} \mathrm{dm}^{-}$ & & & & & $(\%)$ \\
\hline 0 & 6,0 & 17,1 & 0,26 & 2,7 & 1,2 & 0 & 2,0 & 4,16 & 4,16 & 6,16 & 68 & 0 \\
\hline 15 & 6,4 & 151,0 & 1,40 & 7,8 & 3,2 & 0 & 1,8 & 12,30 & 12,38 & 14,18 & 87 & 0 \\
\hline 30 & 6,5 & 208,4 & 3,51 & 8,5 & 4,1 & 0 & 1,7 & 16,00 & 16,05 & 17,75 & 90 & 0 \\
\hline 45 & 6,4 & 238,0 & 4,89 & 16,3 & 3,3 & 0 & 1,8 & 24,40 & 24,41 & 26,21 & 93 & 0 \\
\hline 60 & 6,5 & 248,5 & 6,76 & 34,8 & 2,4 & 0 & 1,9 & 43,80 & 43,85 & 45,75 & 96 & 0 \\
\hline
\end{tabular}

$\mathrm{pH}$ - potencial hidrogeniônico; $\mathrm{P}$ - fósforo; $\mathrm{K}$ - potássio, $\mathrm{Ca}$ - cálcio; $\mathrm{Mg}$ - magnésio; $\mathrm{Al}$ - alumínio; $\mathrm{H}+\mathrm{Al}$ - acidez potencial; $\mathrm{SB}$ - soma de bases; $t$ - CTC efetiva; T - CTC a pH 7,0; V - saturação por bases; $m$ - saturação por alumínio.

plantadas individualmente nos vasos. Os vasos foram distribuídos aleatoriamente, em 4 filas, sobre uma bancada de madeira de $1,2 \mathrm{~m}$ por $10,0 \mathrm{~m}$ e distanciados entre si de, aproximadamente, $0,20 \times 0,25 \mathrm{~m}$. Para diminuir as possíveis diferenças, ao longo do dia, principalmente de sombreamento (incidência de luz solar), e de temperatura do ar no interior do ambiente protegido, foi realizado o rodízio de posição dos vasos, de ponta, de linha e de eixo, a cada 6 dias, seguindo metodologia utilizada por Andreazza et al. (2004) com mudas de eucaliptus.

Durante um período de adaptação de 10 dias após o plantio das estacas (10 DAP), todos os vasos de cada tratamento de substratos receberam a mesma lâmina de irrigação. O cálculo das quantidades de água que foram adicionadas a cada vaso no dia do plantio das estacas, no quarto e no sétimo DAP, foi realizado considerando as médias das quantidades necessárias para que os vasos atingissem o ponto considerado como "capacidade de vaso". Para isso, em 3 vasos de cada tratamento de substratos foi adicionada água manual e lentamente, com provetas de $100 \mathrm{~mL}$ de capacidade e precisão de $0,05 \mathrm{~mL}$ até o momento em que a drenagem do excesso de água pelo fundo dos vasos tivesse início. Nesse procedimento, a água drenada de cada vaso foi retida em um reservatório de plástico sobre o fundo do qual o vaso estava apoiado. Cessada a drenagem, o volume drenado foi medido, com as mesmas provetas, e descontado do volume despejado manual e lentamente, de $100 \mathrm{~mL}$ em $100 \mathrm{~mL}$, em duas ou mais etapas, na superfície do substrato de cada um dos 3 vasos.

No $10^{\circ} \mathrm{DAP}$ e até os $122 \mathrm{DAP}$ as irrigações foram aplicadas a cada 3 dias, tendo como base a evapotranspiração de referência $\left(\mathrm{Et}_{0}\right)$ regional, estimada 
em base diária durante o período experimental, por meio da equação de Penman-Monteith segundo o modelo FAO-56 (Allen et al., 2006), utilizando dados meteorológicos obtidos na estação automatizada oficial da rede do Instituo Nacional de Meteorologia (INMET) instalada na Universidade Federal de Uberlândia. Esses valores de $\mathrm{Et}_{0}$ foram considerados para o tratamento de lâmina de irrigação L3 correspondente a 100\% da $\mathrm{Et}_{0}$. As lâminas correspondentes aos tratamentos L1 $\left(50 \% \mathrm{da} \mathrm{Et}_{0}\right)$ e L2 (75\% da Et $\left.\mathrm{t}_{0}\right)$ corresponderam à lâmina do tratamento L3 multiplicado por 0,5 e 0,75 , respectivamente.

Com o objetivo de evitar a formação de buracos na superfície do substrato, o que poderia provocar drenagem preferencial da água, e ao mesmo tempo possibilitar a sua distribuição de forma heterogênea, foi colocado sobre toda a superfície do substrato, em cada vaso, logo após o plantio das mudas, papel de filtro cortado em formato circular, sobre o qual a água era distribuída.

Em cada irrigação, para que as lâminas de água calculadas para cada um dos tratamentos em função da $\mathrm{Et}_{0}$, em $\mathrm{mm}$, fossem aplicadas sobre a superfície dos substratos de cada vaso com provetas de $100 \mathrm{~mL}$ e resolução de $0,2 \mathrm{~mL}$, as lâminas foram transformadas em volumes, considerando que uma lâmina d'água de um milímetro equivale a 1 litro de água uniformemente distribuído sobre uma área de um metro quadrado $\left(1 \mathrm{~mm}=1 \mathrm{~L} \mathrm{~m}^{-2}\right)$. Como o diâmetro interno dos vasos na altura da superfície dos substratos era de $0,12 \mathrm{~m}$ $(12 \mathrm{~cm})$ correspondendo, portanto, a uma área efetiva de $0,01131 \mathrm{~m}^{2}$, o volume de água (Va), em mL, aplicado em cada irrigação e para cada um dos tratamentos de lâmina de irrigação $\left(\mathrm{mm}\right.$ ou $\left.\mathrm{L} \mathrm{m}^{-2}\right)$ acumulada ao final de cada 3 dias foi obtida com a equação (1).

$$
\mathrm{Va}\left(\% \mathrm{Et}_{0}\right)=\Sigma \mathrm{t}_{0}(3 \text { dias }) \times 0,01131 \times \mathrm{f}\left(\% \mathrm{Et}_{0}\right) \times 1000
$$

Em que:

$\Sigma \mathrm{Et}_{0}$ (3 dias): evapotranspiração de referência acumulada por 3 dias entre as irrigações $\left(\mathrm{L} \mathrm{m}^{-2}\right)$;

$\mathrm{f}\left(\% \mathrm{Et}_{0}\right)$ : fator correspondente ao tratamento de lâmina de irrigação a ser aplicado: 0,5 para $50 \% ; 0,75$ para $75 \%$ e 1,0 para $100 \%$ da $\mathrm{Et}_{0}$;

1000: fator de conversão de L para mL.

Depois de 122 dias de cultivo (122 DAP) as plantas foram cortadas, lavadas e as folhas foram secas em estufa com circulação forçada de ar, à temperatura de $65{ }^{\circ} \mathrm{C}$, durante 84 horas.

A quantificação dos teores de cálcio $(\mathrm{Ca})$ e de ferro $(\mathrm{Fe})$ nas folhas foi feita empregando-se a metodologia recomendada por Tedesco \& Gianello (2004) para tecidos vegetais e os resultados expressos com base em material seco. O processo de digestão da amostra foi a úmida nítrica perclórica e as leituras foram feitas no ICP-OES por espectrometria de emissão atômica com fonte de plasma indutivamente acoplado.

Para ambos os nutrientes a interação entre os fatores composto orgânico e lâminas de irrigação foi avaliada por meio da análise por superfície de resposta para $5 \%$ e $1 \%$ de probabilidade.

\section{RESULTADOS E DISCUSSÃO}

A análise da interação entre doses do composto orgânico no substrato (CO) e lâminas de irrigação (LI) para o teor de Ca nas folhas resultou em modelo significativo $(\mathrm{p}<0,01)$, cuja equação de regressão resultante está apresentada na Tabela 4 e a representação gráfica na Figura 1.

O teor máximo de Ca nas folhas ocorreu com a LI de $90 \%$ da $\mathrm{Et}_{0}$ combinada com o substrato sem composto orgânico $(0 \% \mathrm{CO})$. Na ausência de $\mathrm{CO}$, o teor máximo de $\mathrm{Ca}\left(33,9 \mathrm{~g} \mathrm{~kg}^{-1}\right)$ foi $2,9 \%$ superior ao encontrado para a LI de $50 \%$ da $\mathrm{Et}_{0}\left(32,99 \mathrm{~g} \mathrm{~kg}^{-1}\right) \mathrm{e}$ apenas $0,2 \%$ maior do que na LI de $100 \% \mathrm{da} \mathrm{Et}_{0}$ $\left(33,89 \mathrm{~g} \mathrm{~kg}^{-1}\right)$. O aumento da dose de $\mathrm{CO}$ no substrato de $0 \%$ para $60 \%$ concomitante com a redução da LI de $100 \%$ para $50 \%$ provocou redução crescente no teor de Ca nas folhas, de forma que a combinação da menor LI ( $50 \%$ da $\mathrm{ET}_{0}$ ) com a maior concentração de $\mathrm{CO}$ no substrato $(60 \% \mathrm{CO})$ resultou no menor teor de Ca. A redução verificada do teor máximo de Ca para o mínimo foi de 40,4\% (Tabela 4 e Figura 1).

Mesmo o valor mínimo verificado nesse experimento, de 20,2 $\mathrm{g}$ de Ca por $\mathrm{kg}$ de massa seca da folha, foi superior ao de 13,47 $\mathrm{g} \mathrm{kg}^{-1}$ encontrado por Almeida et al. (2014) em folhas de Ora-pro-nóbis coletadas em plantas de 3 domicílios do município de São Gonçalo do Abaeté (MG). Já o valor máximo encontrado neste experimento, de $33,9 \mathrm{~g} \mathrm{~kg}^{-1}$ foi inferior ao valor mínimo de 44,96 $\mathrm{g} \mathrm{kg}^{-1}$ obtido por Souza et al. (2016) em Ora-pro-nóbis cultivada em solo e na ausência de adubação nitrogenada aplicada em cobertura, e ao 
Tabela 4 - Teor de Ca em folhas de Ora-pro-nóbis. Resumo da análise de variância por meio de superfície de resposta da interação entre doses de composto orgânico (CO) e lâminas de irrigação e equação de regressão resultante (1), valores máximos e mínimos e redução percentual, aos 122 dias após o plantio das estacas

\begin{tabular}{|c|c|c|c|c|c|c|c|}
\hline \multicolumn{2}{|l|}{ Regressão } & \multicolumn{2}{|c|}{ Valor de F } & \multicolumn{2}{|c|}{$\mathrm{p}$} & \multicolumn{2}{|l|}{$\mathrm{R}^{2}$} \\
\hline \multicolumn{2}{|l|}{ Modelo ajustado } & \multicolumn{2}{|c|}{$20,94^{* *}$} & \multicolumn{2}{|c|}{0,0001} & \multicolumn{2}{|c|}{0,92} \\
\hline \multicolumn{7}{|c|}{$\mathrm{Ca}=29,091667-0,484722 \times \mathrm{CO}+0,108 \times \mathrm{LI}+0,003704 \times \mathrm{CO} 2+0,000976 \times \mathrm{CO} \times \mathrm{LI}-0,0006 \times \mathrm{LI}^{2}$} & (1) \\
\hline \multirow{3}{*}{ Valores estimados } & \multicolumn{7}{|c|}{ Teor de Fe } \\
\hline & \multicolumn{3}{|c|}{ Máximo } & \multicolumn{3}{|c|}{ Mínimo } & Redução \\
\hline & $\begin{array}{l}\text { Substrato } \\
\text { (1) } 0 \% \mathrm{CO}\end{array}$ & $\begin{array}{l}\text { Lâmina } \\
90 \% \mathrm{Et}_{0}\end{array}$ & $\begin{array}{c}\text { Valor }\left(\mathrm{mg} \mathrm{kg}^{-1}\right) \\
33,9\end{array}$ & $\begin{array}{l}\text { Substrato } \\
\text { (2) } 60 \% \mathrm{CO}\end{array}$ & $\begin{array}{l}\text { Lâmina } \\
50 \% \mathrm{Et}_{0}\end{array}$ & $\begin{array}{c}\text { Valor }\left(\mathrm{mg} \mathrm{kg}^{-1}\right) \\
20,2\end{array}$ & $\begin{array}{c}(\%) \\
-40,4 \%\end{array}$ \\
\hline
\end{tabular}

** Significativo a $1 \%$ de probabilidade pelo teste $\mathrm{F}$; ${ }^{(1)}$ Substrato sem CO $+100 \%$ mistura de areia média lavada e solo argiloso; ${ }^{(2)}$ Substrato composto por $60 \%$ de $\mathrm{CO}$ e $40 \%$ de solo argiloso.

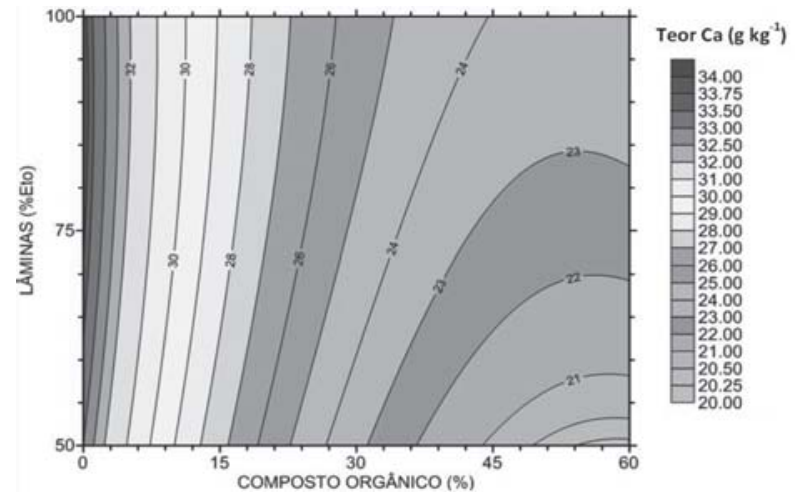

Figura 1 - Superfície de resposta bidimensional com isolinhas para teor de $\mathrm{Ca}$ em folhas de Ora-pro-nóbis em função de doses de composto orgânico no substrato (\%) e de lâminas de irrigação $\left(\% \mathrm{ET}_{0}\right)$, aos 122 dias após o plantio.

mínimo de 54,38 $\mathrm{g} \mathrm{kg}^{-1}$ encontrado por Queiroz (2012) em plantas de Ora-pro-nóbis cultivadas em ambiente protegido e em substrato de solo misturado com areia.

Embora o aumento da dose de $\mathrm{CO}$ no substrato de $0 \%$ para $60 \%$ tenha reduzido o teor de Ca nas folhas em todas as LI, com redução média de $33,8 \%$, o aumento da LI de $50 \%$ para $100 \%$ da $^{2} t_{0}$ aumentou o teor de $\mathrm{Ca}$ em todas as doses de $\mathrm{CO}$, com aumento médio de 19,0\% (Tabela 5).

Verifica-se que na LI de $50 \% \mathrm{da} \mathrm{Et}_{0}$ o efeito deletério do aumento da dose de $\mathrm{CO}$ sobre o teor de $\mathrm{Ca}$ foi maior na LI de $50 \%$ da $\mathrm{Et}_{0}(-38,9 \%)$, intermediário na LI de $75 \%$ da $t_{0}(-33,6 \%)$ e menor na LI de $100 \%$ da $\mathrm{Et}_{0}$
$(-29,2 \%)$. Apesar de ter sido negativo o efeito do aumento da dose de $\mathrm{CO}$ no substrato, o aumento da água disponível para as plantas no substrato, com o aumento da LI de $50 \%$ para $100 \%$ da Et ${ }_{0}$, reduziu o efeito deletério do $\mathrm{CO}$ e foi mais importante quanto maior foi a dose de $\mathrm{CO}$. $\mathrm{Na}$ ausência de $\mathrm{CO}$ no substrato $(0 \%$ de $\mathrm{CO})$, embora os teores de $\mathrm{Ca}$ nas folhas tenham sido os mais elevados para qualquer LI, e com $60 \%$ de CO no substrato tenham sido os menores (Tabela 5 e Figura 1), com $0 \%$ de CO o aumento na LI de $50 \%$ para $100 \%$ da $\mathrm{Et}_{0}$ contribuiu com apenas $2,7 \%$ de aumento no teor de $\mathrm{Ca}$, enquanto que com $60 \%$ de $\mathrm{CO}$ o aumento foi de $19,0 \%$. Isso evidencia a importância do aumento do fluxo transpiratório em função do aumento da disponibilidade de água para as plantas pelo aumento da LI de $50 \%$ para $100 \%$ da $\mathrm{Et}_{0}$, uma vez que o Ca é absorvido pelas raízes e translocado para as folhas por fluxo de massa (Soares et al., 2001; Prado, 2008). No entanto, Queiroz (2012) observou que o teor de Ca em folhas de Ora-pro-nóbis, também cultivada em ambiente protegido, não foi influenciado pela disponibilidade de água no solo quando os potenciais mátricos no solo variaram de $-10 \mathrm{kPa} a-70 \mathrm{kPa}$. Já em cana-de-açúcar, efeito positivo da LI sobre o teor de cálcio nas folhas também foi verificado por Blum, Melfi \& Montes (2012).

A redução nos teores de Ca nas folhas com o aumento das doses de $\mathrm{CO}$ no substrato pode ser explicada pelo efeito da interação entre $\mathrm{K} \mathrm{e} \mathrm{Ca}$, uma vez que, conforme a Tabela 3, com o aumento das doses de CO no substrato, de $0 \%$ para $60 \%$, o porcentual de aumento no teor de $\mathrm{K}$ foi, aproximadamente, de $2500 \%$, enquanto o de $\mathrm{Ca}$ 
Tabela 5 - Redução (") ou aumento (+) percentual do teor de Ca nas folhas em função do aumento da dose de composto orgânico (CO) no substrato e da lâmina de irrigação (LI) aplicada

\begin{tabular}{|c|c|c|c|}
\hline Lâmina $\left(\%\right.$ da $\left.\mathrm{Et}_{0}\right)$ & $\begin{array}{c}\text { Aumento da dose de } \mathrm{CO} \\
\text { no substrato de } 0 \% \text { para } 60 \%\end{array}$ & Dose de CO (\%) & $\begin{array}{c}\text { Aumento da LI de } 50 \% \\
\text { para } 100 \% \mathrm{da}^{\mathrm{Et}}{ }_{0}\end{array}$ \\
\hline \multirow[t]{2}{*}{50} & $-38,9 \%$ & 0 & $+2,7 \%$ \\
\hline & & 15 & $+6,0 \%$ \\
\hline \multirow[t]{2}{*}{75} & $-33,6 \%$ & 30 & $+10,2 \%$ \\
\hline & & 45 & $+14,8 \%$ \\
\hline \multirow[t]{2}{*}{100} & $-29,2 \%$ & 60 & $+19,0 \%$ \\
\hline & & - & - \\
\hline Média & $-33,8 \%$ & Média & $+10,6 \%$ \\
\hline
\end{tabular}

foi menor, aproximadamente, de $1190 \%$. Esse grande incremento de K, segundo Prado (2008), causa decréscimo nos teores de $\mathrm{Ca}$ e $\mathrm{Mg}$. Nesse sentido, teores foliares de até $1,8 \%$ de $\mathrm{K}$ proporcionam diminuição aceitável de $\mathrm{Ca}$ e $\mathrm{Mg}$ foliar com produção satisfatória. Entretanto, níveis mais altos de $\mathrm{K}$ levam à queda muito acentuada nos teores de $\mathrm{Ca}$ e $\mathrm{Mg}$ foliar, de forma que devem ser evitados no manejo da adubação.

Mesmo tendo ocorrido uma redução significativa do teor de Ca nas folhas, de 33,9 $\mathrm{g} \mathrm{kg}^{-1}$ para 20,2 g $\mathrm{kg}^{-1}$, com o aumento de $\mathrm{CO}$ de $0 \%$ para $60 \%$ na constituição do substrato, respectivamente (Tabela 4), esses valores podem ser considerados satisfatórios, pois segundo Kerbauy (2004) a demanda de Ca pelas plantas, para um crescimento ótimo, está dentro da faixa de concentração de 10 a $50 \mathrm{~g} \mathrm{~kg}^{-1} \mathrm{em}$ base seca, dependendo da espécie e da parte da planta. Nos estudos de Souza et al. (2005), os teores foliares de cálcio nas plantas de alface não foram influenciados pelas doses de composto orgânico, e pela presença de adubo mineral. Os teores de Ca da parte aérea da alface oscilaram de 11,7 a $13,7 \mathrm{mg} \mathrm{kg}^{-1}$ de massa seca. No entanto, Rodrigues \& Casali (1991) e Vidigal et al. (1995), também em alface, constataram decréscimos nos teores de Ca na parte aérea das plantas, com a elevação das doses de composto orgânico no substrato.

Com relação ao teor de Fe nas folhas, o modelo de superfície de resposta foi significativo $(\mathrm{p}<0,01)$ para a interação CO x LI. Os valores máximo e mínimo foram estimados por meio da equação (2), em 724,05 $\mathrm{mg} \mathrm{kg}^{-1}$ com $0 \%$ de CO e LI de $100 \%$ da Et ${ }_{0}$, e $415,88 \mathrm{mg} \mathrm{kg}^{-1}$ com $60 \%$ de CO e LI de $65 \%$ da $\mathrm{Et}_{0}$, respectivamente (Tabela 6).

A análise das isolinhas do teor de Fe em função do $\mathrm{CO}$ e da LI apresentadas na Figura 2 e dos dados da Tabela 7 evidenciou o efeito altamente negativo do aumento da dose de CO no substrato, independentemente da lâmina de irrigação aplicada entre $50 \%$ e $100 \%$ da Et $t_{0}$, com redução média de $39,0 \%$. $\mathrm{O}$ efeito do aumento da LI foi positivo dentro das doses de $\mathrm{CO}$ (média de $5,8 \%$, variando de $6,3 \%$ em $0 \%$ de $\mathrm{CO}$ a $5,5 \%$ em $45 \%$ e $60 \%$ de CO), mas muito menos importante do que a redução provocada pelo aumento da dose de CO. Na medida em que o percentual de $\mathrm{CO}$ no substrato vai aumentando as isolinhas vão se tornando mais paralelas ao eixo das LI o que caracteriza a diminuição do efeito positivo do aumento da LI com o aumento das doses de CO. Dentre os constituintes das folhas de Ora-pro-nóbis, o Fe, juntamente com as proteínas, é um dos nutrientes que despertam mais interesse visto que atua no combate e prevenção à anemia. Os teores médios de $\mathrm{Fe}$ nas folhas encontrados neste trabalho (415,88 a 724,05 $\mathrm{mg} \mathrm{kg}^{-1}$; Tabela 6) são bastante elevados se comparados aos teores de $\mathrm{Fe}$ em folhas de algumas hortaliças convencionais e não convencionais relacionadas por TACO (2011), conhecidas pela maior parte da população, como a alface americana (107 $\left.\mathrm{mg} \mathrm{kg}^{-1}\right)$, a alface crespa (102 $\left.\mathrm{mg} \mathrm{kg}^{-1}\right)$, a chicória (102 $\left.\mathrm{mg} \mathrm{kg}^{-1}\right)$, a couve-flor $\left(69 \mathrm{mg} \mathrm{kg}^{-1}\right)$, o repolho branco $\left(38 \mathrm{mg} \mathrm{kg}^{-1}\right)$ e a taioba $\left(176 \mathrm{mg} \mathrm{kg}^{-1}\right)$. Em relação a outros trabalhos com Ora-pro-nóbis, os valores encontrados são superiores aos encontrados por Queiroz (2012), de 156,50 $\mathrm{mg} \mathrm{kg}^{-1}$, por Almeida et al. (2014), de 205,6 $\mathrm{g} \mathrm{kg}^{-1}$ e por Souza et al. (2016), de $199,7 \mathrm{~g} \mathrm{~kg}^{-1}$. De acordo com Borket, Pavan e Bataglia (2001), são considerados teores médios de Fe nas plantas entre $50 \mathrm{e}$ $250 \mathrm{mg} \mathrm{kg}^{-1}$, sendo que valores acima de $1000 \mathrm{mg} \mathrm{kg}^{-1}$ geralmente são associados à toxicidade.

A redução do teor de Fe nas folhas com o aumento da dose do CO no substrato pode ser explicada pela 
Tabela 6 - Teor de ferro em folha de Ora-pro-nóbis. Resumo da análise estatística e equação de regressão para a superfície de resposta (2), valores máximos e mínimos e respectivas combinações entre o porcentual de composto orgânico na composição do substrato (x - CO - \%) e lâminas de irrigação (y - LI - \% Et E $_{0}$, aos 122 dias após o plantio das estacas

\begin{tabular}{|c|c|c|c|c|c|c|c|}
\hline \multicolumn{2}{|l|}{ Regressão } & \multicolumn{2}{|c|}{ Valor de F } & \multicolumn{2}{|c|}{$\mathrm{p}$} & \multicolumn{2}{|l|}{$\mathrm{R}^{2}$} \\
\hline \multicolumn{2}{|l|}{ Modelo ajustado } & \multicolumn{2}{|c|}{$10,96^{* *}$} & \multicolumn{2}{|c|}{0,0013} & \multicolumn{2}{|c|}{0,86} \\
\hline \multicolumn{7}{|c|}{$\mathrm{Fe}=751,85-1,945 \times \mathrm{CO}-2,558 \times \mathrm{LI}-0,034259 \times \mathrm{CO}^{2}-0,006667 \times \mathrm{CO} \times \mathrm{LI}+0,0228 \times \mathrm{LI}^{2}$} & (2) \\
\hline \multirow{3}{*}{ Valores estimados } & \multicolumn{7}{|c|}{ Teor de Fe } \\
\hline & \multicolumn{3}{|c|}{ Máximo } & \multicolumn{3}{|c|}{ Mínimo } & Redução \\
\hline & $\begin{array}{l}\text { Substrato } \\
\text { (1) } 0 \% \mathrm{CO}\end{array}$ & $\begin{array}{c}\text { Lâmina } \\
100 \% \mathrm{Et}_{0}\end{array}$ & $\begin{array}{c}\text { Valor }\left(\mathrm{mg} \mathrm{kg}^{-1}\right) \\
724,05\end{array}$ & $\begin{array}{l}\text { Substrato } \\
\text { (2) } 60 \% \mathrm{CO}\end{array}$ & $\begin{array}{l}\text { Lâmina } \\
65 \% \mathrm{Et}_{0}\end{array}$ & $\begin{array}{c}\text { Valor }\left(\mathrm{mg} \mathrm{kg}^{-1}\right) \\
415,88\end{array}$ & $\begin{array}{c}(\%) \\
-42,6 \%\end{array}$ \\
\hline
\end{tabular}

** Significativo a $1 \%$ de probabilidade pelo teste $\mathrm{F}$; ${ }^{(1)}$ Substrato sem CO + 60\% de areia média lavada e $40 \%$ de solo argiloso (79,1\% de argila); (2) Substrato composto por $60 \%$ de $\mathrm{CO}$ e $40 \%$ de solo argiloso (79, $1 \%$ de argila).

Tabela 7 - Redução (-) ou aumento (+) percentual do teor de Fe nas folhas em função do aumento da dose de composto orgânico (CO) no substrato ou da lâmina de irrigação (LI) aplicada

\begin{tabular}{|c|c|c|c|}
\hline $\begin{array}{l}\text { Lâmina } \\
\left(\% \text { da } \mathrm{Et}_{0}\right)\end{array}$ & $\begin{array}{l}\text { Aumento da dose de CO no } \\
\text { substrato de } 0 \% \text { para } 60 \%\end{array}$ & Dose de $\mathrm{CO}(\%)$ & $\begin{array}{c}\text { Aumento da lâmina de irrigação } \\
\text { de } 50 \% \text { para } 100 \% \text { da } \mathrm{Et}_{0}\end{array}$ \\
\hline \multirow[t]{2}{*}{50} & $-38,2 \%$ & 0 & $+6,3 \%$ \\
\hline & & 15 & $+6,0 \%$ \\
\hline \multirow[t]{2}{*}{75} & $-39,2 \%$ & 30 & $+5,7 \%$ \\
\hline & & 45 & $+5,5 \%$ \\
\hline \multirow[t]{2}{*}{100} & $-38,7 \%$ & 60 & $+5,5 \%$ \\
\hline & & - & - \\
\hline Média & $-39,0 \%$ & Média & $+5,8 \%$ \\
\hline
\end{tabular}

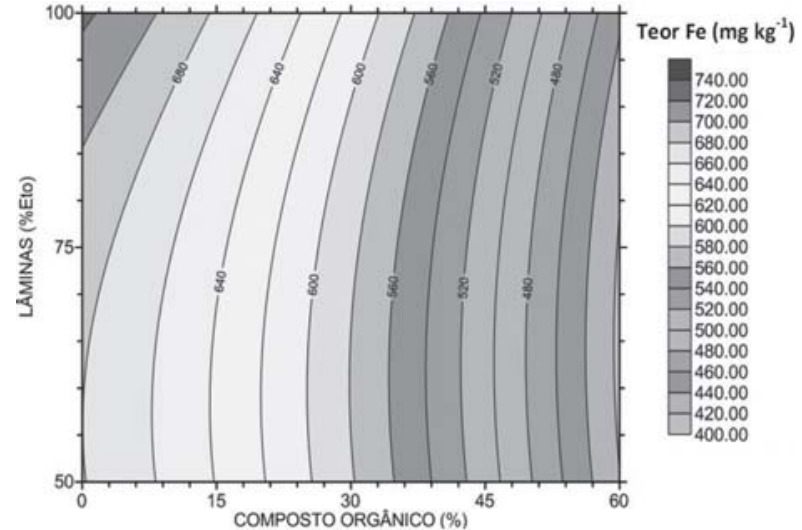

Figura 2 - Superfície de resposta bidimensional com isolinhas para teor de $\mathrm{Fe}$ em folhas de Ora-pro-nóbis em função de doses de composto orgânico no substrato (\%) e de lâminas de irrigação $\left(\% \mathrm{Et}_{0}\right)$, aos 122 dias após o plantio. interação P-Fe que, segundo Kabata-Pendias \& Pendias (2001), comumente ocorre tanto no metabolismo da planta como no solo. Nos substratos utilizados nesta pesquisa, o incremento na concentração de $\mathrm{P}$ com o aumento nas doses de $\mathrm{CO}$ de $0 \%$ para $60 \%$, foi de aproximadamente $1553 \%$ (de 17,1 para $248,5 \mathrm{mg} \mathrm{dm}^{-3}$, respectivamente; Tabela 3). A afinidade entre $\mathrm{Fe}^{3+} \mathrm{e}$ $\mathrm{H}_{2} \mathrm{PO}_{4}^{-}$é alta e, dessa forma, a precipitação de $\mathrm{FePO}_{4} \cdot \mathrm{H}_{2} \mathrm{O}$ pode facilmente ocorrer sob condições favoráveis. Assim os ânions fosfato competem com a planta em relação ao ferro e isso interfere não só na absorção, mas também no transporte interno do nutriente. Para Elliott \& Läuchli (1985), entre os mecanismos propostos para explicar o decréscimo da absorção de ferro pelas plantas, em condições de elevados teores de fósforo, incluem-se a imobilização do ferro na solução do solo, a inibição da absorção de ferro pelas raízes e transporte das raízes até a parte aérea. Os substratos testados neste experimento apresentavam níveis crescentes 
de manganês em função do aumento do porcentual de CO (Tabela 2), cuja análise inicial indicou $706 \mathrm{mg}$ $\mathrm{kg}^{-1}$ (Tabela 1). A interação $\mathrm{Fe}-\mathrm{Mn}$ é bastante comum, sendo que o aumento dos níveis de Mn, com o aumento das doses de $\mathrm{CO}$ nos substratos, pode ter influenciado no decréscimo do teor de Fe (Reisenauer, 1994), possivelmente devido à redução na absorção e na translocação de Fe (Kabata-Pendias \& Pendias, 2001).

\section{CONCLUSÕES}

Os teores de Ca e de Fe nas folhas de Ora-pro-nóbis são influenciados pela presença de composto orgânico no substrato de cultivo e pela quantidade de água recebida pela cultura por irrigação.

O aumento da lâmina de irrigação de 50\% para $100 \%$ da evapotranspiração de referência aumenta os teores de $\mathrm{Ca}$ e de $\mathrm{Fe}$, enquanto o aumento das doses de composto orgânico no substrato de $0 \%$ para $60 \%$ tem efeito deletério sobre os teores desses elementos nas folhas de Ora-pro-nóbis.

\section{AGRADECIMENTOS}

À Coordenadoria de Aperfeiçoamento de Pessoal do Ensino Superior (CAPES), à Universidade Estadual Paulista (UNESP) e ao Instituto Federal do Triângulo Mineiro (IFTM).

\section{LITERATURA CITADA}

ABREU JÚNIOR, C. H.; MURAOKA, M.; OLIVEIRA, F. C. Cátions trocáveis, capacidade de troca de cátions e saturação por bases em solos brasileiros adubados com composto de lixo urbano. Scientia Agrícola, v. 58, n. 4, p. 813-824, 2001. Disponível em: <https:// www.researchgate.net/journal/01039016_Scientia_Agricola $>$ (acessado em 27 novembro 2018).

ALLEN, R. G.; PEREIRA, L. S.; RAES, D.; SMITH, M. Evapotranspiración del cultivo: guías para la determinación de los requerimientos de agua de los cultivos. Estudio FAO - Riego y Drenaje 56. Roma, 2006. 298 p. Disponível em: <http://www.fao.org/ docrep/pdf/009/x0490s/x0490s.pdf $>$ (acessado em 27 novembro 2018).
ALMEIDA, M. E. F.; JUNQUEIRA, A. M. B.; SIMÃO, A. A.; CORRÊA, A. D. Caracterização química das hortaliças não-convencionais conhecidas como Ora-pro-nóbis. Bioscience Journal, v.30, sup.1, p.431-439, 2014. Disponível em: <http://www.seer.ufu.br/index.php/ biosciencejournal/article/view/17555/14557> (acessado em 20 março de 2018).

ANDREAZZA, R.; ANTONIOLLI, Z. I.; SILVA, R. F. S.; LONGHI, S. J. Espécies de Pisolitus sp. na produção de mudas de Eucalyptus grandis Hill ex Maiden em solo arenoso. Ciência Florestal, v.14, n.2, p.51-59, 2004. Disponível em http:// www.scielo.br/pdf/cflo/v14n2/1980-5098-cflo-14-0200051.pdf (acessado em 27 de novembro de 2018).

BEZERRA, J. R. C.; DIAS, J. M.; PEREIRA, J. R.; GUEDES, F. X. Consumo hídrico do algodoeiro BRS 200 Marron. Campina Grande: EMBRAPA, 2009. (Circular Técnica 129). Disponível em $<$ https://www.infoteca.cnptia.embrapa.br/bitstream/ doc/748452/1/CIRTEC129> (acessado em 27 novembro 2018).

BLUM, J.; MELFI, A. J.; MONTES, C. R. Nutrição mineral da cana de açúcar irrigada com efluente e esgoto tratado, em área com aplicação de fosfogesso. Pesquisa Agropecuária Brasileira, v.47, n.4, p.593-602, 2012. Disponível em <http:// seer.sct.embrapa.br/index.php/pab/article/view/ 12105> (acessado em 27 novembro 2018).

BORKET, C. M.; PAVAN, M. A. E.; BATAGLIA, O. C. Disponibilidade e avaliação de elementos catiônicos: ferro e manganês. In: FERREIRA, M. F.; CRUZ, M. C. P.; RAIJ, B.; ABREU, C. A. Micronutrientes e elementos tóxicos na agricultura. Jaboticabal, SP: CNPq/FAPESP/ POTAFOS, 2001. Cap. 7, p. 151-185.

BRASIL. Manual de hortaliças nãoconvencionais. Mnistério da Agricultura, Pecuária e Abastecimento. Belo Horizonte, MG, 2010. 92p. Disponível em $<$ http://www.abcsem.com.br/docs/ manual_hortalicas_web.pdf $>$ (acessado em $7 \mathrm{de}$ outubro de 2018).

ELLIOTT, G. C.; LÄUCHLI, A. Phosphorus efficiency and phosphate-Iron interaction in maize. Agronomy Journal, v.77, n.3, p.399-403, 1985. D.O.I. 10.2134/ agronj1985.00021962007700030011x 
EMBRAPA. EMPRESABRASILEIRADE PESQUISA AGROPECUÁRIA. Sistema brasileiro de classificação de solos. 3. ed. Rio de Janeiro, 2013.353 p.

FERREIRA, V. M.; MAGALHÃES, P. C.; DURÃES, F. O. M.; VASCONCELLOS, C. A.; ARAÚJO NETO, J. C. Acúmulo e distribuição de macronutrientes em dois híbridos duplos de milho, em função da disponibilidade de água no solo. Revista Brasileira de Milho e Sorgo, v.7, n.1, p.1-17, 2008. Disponível em < https://www.alice.cnptia.embrapa.br/bitstream/ doc/491629/1/Acumulodistribuicao.pdf $>$ (acessado em 8 de outubro de 2018).

FRANCO, G. Tabela de composição química dos alimentos. 9 ed. São Paulo: Atheneu, 2004. 307 p.

KABATA-PENDIAS, A.; PENDIAS, H. Trace elements in soils and plants. $3^{\text {rd }}$ edition: Boca Raton CRC Press, 2001. 413 p.

KERBAUY, G. B. Fisiologia vegetal. Guanabara Koogan: Rio de Janeiro, 2004. p.1-75.

KIEHL, E. J. Novo fertilizantes orgânicos. Piracicaba, SP: Degaspari, 2010.

KINUPP, V. F.; BARROS, I. B. I. Teores de proteína e minerais de espécies nativas, potenciais hortaliças e frutas. Ciência e Tecnologia de Alimentos, v.28, n.4, p.846-857, 2008. Disponível em $<$ http://www.scielo.br/ scielo.php?script $=$ sci_arttext\&pid $=\mathrm{S} 0101$ $20612008000400013>$ (acessado em 8 outubro de 2018).

PRADO, R. D. M. Nutrição mineral de plantas. Jaboticabal: UNESP, 2008. p.9-29, 53-62, 181-200, 259-270, 341-353.

QUEIROZ., C. R. A. A. Cultivo e composição química de Ora-pro-nóbis (Pereskia aculeata Mill.) sob déficit hídrico intermitente no solo. 2012. 144 f. Tese (Doutorado em Agronomia Ciência do Solo) - Universidade Estadual Paulista, Faculdade de Ciências Agrárias e Veterinárias. Jaboticabal, SP, 2012.

REISENAUER, H. M. The interaction of manganese and iron. In: Biochemistry of metal micronutrients in the rhizosphere. Boca Raton: Lewis Publishers, 1994. p.147-164.
RODRIGUES, E. T.; CASALI, V. W. A. Efeito da adubação orgânica sobre o $\mathrm{pH}$ e a condutividade elétrica em solos cultivados com alface. Horticultura Brasileira, v. 9, n. 1, p. 162-164, 1991.

SILVA JÚNIOR, J. V.; BECKMANNCAVALCANTE, M. Z.; BRITO, L. P. S.; AVELINO, R. C.; CAVALCANTE, I. H. L. Aproveitamento de materiais alternativos na produção de mudas de tomateiro sob adubação foliar. Revista Ciência Agronômica, v. 45, n. 3, p. 528-536, 2014. Disponível em < http:// ccarevista.ufc.br/seer/index.php/ccarevista/ article/view/1848> (acessado em 30 de julho de 2018).

SOARES, C. R. F. S.; GRAZZIOTTI, P. H.; SIQUEIRA, J. O.; CARVALHOA, J. G. E.; MOREIRA, F. M. S. Toxidez de zinco no crescimento e nutrição de Eucalyptus maculata e Eucalyptus urophylla em solução nutritiva. Pesquisa Agropecuária Brasileira, v.36, n.2, p.339-348, 2001. Disponível em < http:// www.scielo.br/pdf/pab/v36n2/a18v36n2.pdf> (acessado em 28 de julho de 2018).

SOUZA, P. A.; NEGREIROS, M. Z.; MENEZES, J. B.; BEZERRA NETO, F.; SOUZA, G. L. F. M.; CARNEIRO, C. R.; QUEIROGA, R. C. F.

Características químicas de folhas de alface cultivada sob efeito residual da adubação com composto orgânico. Horticultura Brasileira, v. 23, n. 3, p. 754-757, 2005. Disponível em < http:/ /www.scielo.br/pdf/\%0D/hb/v23n3/ a13v23n3.pdf> (acessado em 20 de julho de 2018).

SOUZA, M. R. de M; PEREIRA, P. R. G.; MAGALHÃES, I. P. B.; SEDYIAMA, M. A. N.; VIDIGAL, S. M.; MILAGRES, C. S. F.; BARACAT-PEREIRA; M. C. Mineral, protein and nitrate contents in leaves of Pereskia aculeate subjected to nitrogen fertilization. Pesquisa Agropecuária Tropical, v. 46, n. 1, p. 43-50, 2016. Disponível em < http:// www.scielo.br/pdf/pat/v46n1/1517-6398-pat-4601-0043.pdf $>$ (acessado em 25 de julho de 2018).

TACO: Tabela brasileira de composição de alimentos / NEPA - UNICAMP. $4^{\text {a }}$ ed. revisada e ampliada. Campinas: NEPAUNICAMP, 2011. $161 \mathrm{p}$. 
TAKEITI, C. Y.; ANTONIO, G. C.; MOTTA, E. M. P.; COLARES-QUEIROZ, F. P.; PARK, K. J. Nutritive evaluation of a non-convencional leafy vegetable (Pereskia aculeata Miller). International Journal of Food Science and Technology, v. 1, n. 60, p.148-160, 2009. Disponível em <https:// www.ncbi.nlm.nih.gov/pubmed/19468927> (acessado em 20 de julho de 2018).

TEDESCO, M. J.; GIANELLO, C. Metodologia de análises de solo, plantas, adubos orgânicos e resíduos. In: BISSANI, C. A. et al. (Eds.).

Fertilidade dos solos e manejo da adubação de culturas. Porto Alegre: Gênesis, 2004. p.61-66.
TOFANELLI, M. B. D.; RESENDE, S. G. Sistema de condução na produção de folhas de ora-pronóbis. Pesquisa Agropecuária Tropical, v.41, n.3, p.466-69, 2011. Disponível em < http://dx.doi.org/ 10.5216/pat.v41i3.12497> (acessado em 28 de julho de 2018).

VIDIGAL, S. M.; RIBEIRO, A. C.; CASALI, V. W. D.; FONTES, L. E. F. Resposta da alface (Lactuca sativa L.) ao efeito residual da adubação orgânica II - ensaio de casa de vegetação (b). Revista Ceres, v. 42, n. 239, p. 89-97, 1995.

Recebido para publicação em 26/02/2019 e aprovado em 26/06/2019. 